\title{
3D-printed Prostheses Assisted by Osteotomy Guide Plates for Reconstruction Following Periacetabular Tumor Resection via Two Approaches
}

\author{
Yong-jie Zhao \\ Tianjin Hospital \\ Jing-yu Zhang \\ Tianjin Hospital \\ Xiao-qiang Deng \\ Tianjin Medical University \\ Xin-chong Du \\ Tianjin Medical University \\ Hao Zhang \\ Tianjin Medical University \\ Li Yang \\ Tianjin Medical University

\section{Yong-cheng $\mathrm{Hu}$} \\ Tianjin Hospital \\ Xin-long Ma ( $\sim$ tjyymaxinlong@126.com ) \\ Tianjin Hospital https://orcid.org/0000-0003-3318-9068
}

Research article

Keywords: Periacetabular tumor, 3D-printed prostheses, Osteotomy Guide Plate, Surgical approach

Posted Date: January 11th, 2021

DOl: https://doi.org/10.21203/rs.3.rs-141473/v1

License: @ (i) This work is licensed under a Creative Commons Attribution 4.0 International License. Read Full License 


\section{Abstract}

Background: Prosthetic reconstruction after periacetabular tumor resection likely yield good function. However, complications with this technique are common. Therefore, alternative prosthetic design and surgical technique warrant study.

Methods: Six patients were retrospectively reviewed with malignant periacetabular tumors who received reconstruction using 3D-printed prostheses assisted by osteotomy guide plates via two approaches between July 2017 and June 2020. The surgical data, including operative duration and intraoperative blood loss were recorded. Preoperative and postoperative pain at rest was examined using the visual analog scale (VAS). The postoperative functional outcomes were evaluated using the Musculoskeletal Tumor Society (MSTS) scoring system, and the postoperative complications were analyzed.

Results: The mean follow-up was 19 months (range, 3-36 months). The mean intraoperative blood loss was $1416 \mathrm{ml}$ (range, 600-2000 ml), and the mean operative duration was $333 \mathrm{~min}$ (range, 300-370 min). Satisfactory surgical margins were achieved in all patients. Six patients complained of severe pain preoperatively (VAS score, mean, 6; range, 4-8) and described significant alleviation of pain at 4 weeks postoperatively (VAS score, mean, 2; range, 0-5). At the 12 weeks after surgery, the mean MSTS score was 15.6 (range, 5-27). Local recurrence occurred in one patient at 3 months after surgery.

Conclusions: The 3D-printed prosthesis represents a potential alternative for reconstruction after malignant periacetabular tumor resection. The design of the two approaches and the use of osteotomy guide plates can yield good functional results, as well as low rate of complications.

Trial registration: This study has been granted an exemption from requiring ethics approval by the ethics committee of Tianjin Hospital.

\section{Background}

The pelvis is the third most common area of bone metastasis and accounts for $10-15 \%$ of primary malignant bone tumors [1-4]. Wide en bloc resection is a standard treatment for malignant periacetabular tumor. Once pelvic integrity is disrupted, it often results in fecal/urinary incontinence, prolapse and hernia [5-7]. Thus, bone defect reconstruction after tumor resection is critical for patients with malignant pelvic tumors.

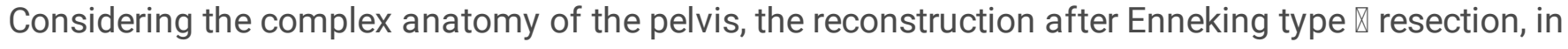
particular, pose great challenges to orthopedic oncologists [8,9]. As a result of severe physical and psychological disability following hemipelvectomy [10-12], limb-salvage procedures have gradually become more recommended by surgeons [12-14].

Some biological and prosthetic reconstructive techniques $[1,3,11,15-23]$ have been used in malignant periacetabular bone tumor surgery. Nevertheless, a high rate of $75 \%$ complications inevitably occurs after reconstructive surgery with these techniques $[8,24]$. Although pelvic reconstruction using 3D-printed prostheses assisted by a surgical navigation system can enable precise osteotomy and implant installation, it may increase the operative duration and blood loss [25], which negatively impact the rate of infection and wound-related complications $[2,26]$. Thus, the optimal technique for reconstruction remains controversial. 
Therefore, we performed reconstruction after malignant periacetabular tumor resection with 3D-printed prostheses assisted by osteotomy guide plates via two approaches (Fig. 1). The purpose was to 1) introduce the procedure of malignant periacetabular tumor resection and reconstruction via two approaches and 2) evaluate the preliminary results with this new technique.

\section{Methods}

\section{Patient Characteristics}

We retrospectively reviewed patients who underwent surgery for malignant periacetabular tumors between July 2017 and June 2020 and ultimately enrolled 6 patients in the study. According to the Enneking staging system [27], one patient with acinar soft tissue sarcoma was stage III, and the other three primary tumors were stage IIB. The patient demographic data was summarized in Table 1.

Table 1

clinical characteristics of the patients

\begin{tabular}{|c|c|c|c|c|c|c|c|c|}
\hline $\begin{array}{l}\text { patient } \\
\text { number }\end{array}$ & $\begin{array}{l}\text { Age } \\
\text { (years) }\end{array}$ & Gender & $\begin{array}{l}\text { Histologic } \\
\text { type }\end{array}$ & $\begin{array}{l}\text { Stage } \\
\text { type }\end{array}$ & $\begin{array}{l}\text { Adjuvant } \\
\text { therapy }\end{array}$ & $\begin{array}{l}\text { Resection } \\
\text { tpye }\end{array}$ & $\begin{array}{l}\text { Surgical } \\
\text { margin }\end{array}$ & $\begin{array}{l}\text { Tumor } \\
\text { size } \\
\left(\mathrm{cm}^{3}\right)\end{array}$ \\
\hline 1 & 32 & $\mathrm{~F}$ & $\begin{array}{l}\text { Soft tissue } \\
\text { Sarcoma }\end{array}$ & Q & Yes & $\nabla+\rrbracket$ & Marginal & $\begin{array}{l}9.5 \times \\
7 \times 6\end{array}$ \\
\hline 2 & 69 & $M$ & Renal cancer & \# & No & $\nabla+\nabla$ & Wide & $\begin{array}{l}12 \times 9 \\
\times 5\end{array}$ \\
\hline 3 & 69 & $\mathrm{~F}$ & Breast cancer & $\#$ & No & $\nabla+\rrbracket$ & Wide & $\begin{array}{l}7.5 \times \\
5 \times 3.2\end{array}$ \\
\hline 4 & 34 & $M$ & chondrosarcoma & $\bigotimes \mathrm{B}$ & No & $\nabla+\square$ & Wide & $\begin{array}{l}4 \times 2 \\
\times 2\end{array}$ \\
\hline 5 & 57 & $M$ & chondrosarcoma & $\bigotimes \mathrm{B}$ & No & $\nabla+\rrbracket$ & Wide & $\begin{array}{l}5 \times 4 \\
\times 2\end{array}$ \\
\hline 6 & 52 & $\mathrm{~F}$ & osteosarcoma & $\triangle \mathrm{B}$ & Yes & $\nabla+\rrbracket$ & Wide & $\begin{array}{l}14.5 \times \\
12 \times \\
7.3\end{array}$ \\
\hline
\end{tabular}

\section{Preoperative planning}

\section{Osteotomy Guide Planning}

Before the operation, a proportional 3D pelvic model was reconstructed based on the original CT data (Fig. 2). When ascertaining the osteotomy planes, the spread of the tumor within the bone must be taken into account. 
Meanwhile, tumor cutting lines should be kept $30 \mathrm{~mm}$ from the tumor response zone to maintain a tumor-free margin. Then, osteotomy guide plates were manufactured by a 3D printing machine (Fig. 3a囚3b).

\section{Prostheses Manufacture}

According to mirror imaging of the unaffected hemi-pelvic combined with the projected osteotomy extent, we designed 3D individualized titanium alloy prostheses adaptable to the residual pelvis using electronic beam melting technology. At the implant-bone interface, a porous structure was designed to promote bone in-growth (Fig. 3c). The pore diameter and porosity were set to $500 \mu \mathrm{m}$ and $70 \%$, respectively. Several screw holes for fixation were predrilled in the prostheses. The position and length were planned based on the bone thickness, residual bone mass and loading orientation to minimize shear stress (Fig. 3d). Surgeons simulated the osteotomy procedure in a hemi-pelvic model of the affected side with projected osteotomy guide plates and validated the compatibility of the prostheses with the bone defect multiple times.

\section{Surgical Procedure}

\section{Ilioinguinal approach}

After general anesthesia, the incision started at the anterosuperior iliac spine and progressed over the inguen to the pubic symphysis. Care was taken to identify and protect the iliopsoas tendon and femoral neurovascular bundles. Part of or the whole iliac muscle was divided from the iliac inner plate. The gluteus maximus and medius were preserved, and the gluteus minimus was usually detached to obtain a wide surgical margin. Then, the sciatic notch and sciatic spine were visualized. For II + III resection, the pubis ramus and even the contralateral pubis were exposed. The upper iliac and pubis osteotomy guide plates were seated and fixed using 2.0-mm Kirschner wires.

\section{Kocher-Langenbeck approach}

Then, the patient was placed in a slight anteversion position, and the Kocher-Langenbeck approach was adopted. The hip joint capsule was exposed and subsequently incised after removing the external rotation muscle group. Osteotomy of the femoral neck was carried out $15 \mathrm{~mm}$ above the lesser trochanter. Following femoral head removal, the contour of the tumor was thoroughly visualized. The other osteotomy guide plates were firmly placed on the surface of the ischium. Assisted with these guide plates, we conducted osteotomy precisely with a 1.0-mm oscillating saw. The sacrotuberal and sacrospinal ligaments needed to be dissected from the safe nontumor margin before the intact tumor was removed.

\section{Prostheses positioning}

Microwaves were also taken into account to ascertain whether a safe resection margin had been achieved. A 3D-printed individualized prosthesis was selected to fit the contour of the residual pelvic. Before fixation, the inclination and anteversion of the acetabular cup were evaluated, and cancellous screws were used to augment the prostheses through predrilled holes. Subsequently, conventional total hip arthroplasty was carried out. The ultimate goal was to regain the integrity of the pelvic ring and function of the hip joint. (Fig. 4). An additional movie file shows this in more detail [see Additional file 1]. 


\section{Postoperative Management}

Two drainage tubes were routinely placed during surgery and were removed when the daily volume was < $30 \mathrm{ml}$. Compression bandages were sometimes needed to diminish dead space. First-generation cephalosporins was administered until the drainage tube removed. Patients were advised to walk with a crutch or walking aid 4 weeks after surgery, and full weightbearing was encouraged 6 weeks postoperatively.

\section{Follow-up}

All patients were available for scheduled follow-up visits for a maximum of 36 months (mean, 19 months; range, 3-36 months). Clinical and radiological examinations were conducted every two months in the first year and four times each year thereafter.

\section{Results}

\section{Oncological outcome}

At the finial follow-up, three patients with primary tumors were alive with no evidence of disease. One patient with metastatic renal cancer was alive with no recurrence. One patient with acinar soft tissue sarcoma had a local recurrence and metastasis at 3 months and died of the disease at 12 months postoperatively. The other one patient with metastatic breast cancer died of the disease at 28 months after surgery.

\section{Operative Outcome}

The mean intraoperative blood loss was $1416 \mathrm{ml}$ (range, 600-2000 ml), and the mean operative duration was 333 min (range, 300-370 min). (Table 2). Satisfactory surgical margins were achieved in all patients, including wide margins in 5 patients (83.3\%) and marginal margins in 1 patient $(16.7 \%)$. The patient with acinar soft tissue sarcoma underwent marginal excision because the tumor had invaded the sciatic nerve. However, the patient had a good preoperative response to chemotherapy.

\section{Functional Outcome}

\section{MSTS score}

At the 12weeks after surgery, the mean Musculoskeletal Tumor Society (MSTS) score [28] was 18.7 (range, 13-27). (Table 3). Three patients could walk without any aids, two patients could walk with one crutch, and one patient could walk with two crutches.

\section{VAS Score}

In the study, six patients complained of severe pain preoperatively (visual analog scale (VAS) score, mean, 6; range, 4-8) and needed anti-inflammatory drugs. They described significant alleviation of pain at 4 weeks postoperatively (VAS score, mean, 2; range, $0-5$ ). 


\section{Complications}

As the classification described by Henderson [29], complications of this series were recorded in Table 3 .

Table 2

The studies of surgical details in literatures

\begin{tabular}{|lllll|}
\hline Study & $\begin{array}{l}\text { Case } \\
\text { numbers }\end{array}$ & $\begin{array}{l}\text { Reconstructive } \\
\text { method }\end{array}$ & $\begin{array}{l}\text { Operative } \\
\text { time(mins) }\end{array}$ & $\begin{array}{l}\text { Intraoperative blood loss } \\
\text { (ml) }\end{array}$ \\
\hline Current study & 6 & 3D printed prosthesis & 333 & 1416 \\
\hline Ji et al [22] (2020) & 80 & Modular prosthesis & 445 & 2230 \\
\hline $\begin{array}{l}\text { Park et al [7] } \\
(2020)\end{array}$ & 12 & 3D printed prosthesis & 206 & 3236 \\
$\begin{array}{l}\text { Wang et al [21] } \\
(2018)\end{array}$ & 11 & CAD prosthesis & 271 & 2585 \\
\hline $\begin{array}{l}\text { Irene et al [19] } \\
(2017)\end{array}$ & 10 & $\begin{array}{l}\text { Ice-Cream Cone } \\
\text { prosthesis }\end{array}$ & 419 & 1982 \\
\hline $\begin{array}{l}\text { Cernat et al [36] } \\
(2016)\end{array}$ & 4 & APCs & 446 & 3130 \\
\hline $\begin{array}{l}\text { Guo et al [32] } \\
(2010)\end{array}$ & 18 & Combined prosthesis & 291 & 6210 \\
\hline $\begin{array}{l}\text { Dai et al [11] } \\
(2007)\end{array}$ & 10 & $\begin{array}{l}\text { Custom-made } \\
\text { prosthesis }\end{array}$ & $\#$ & \\
\hline \# = not mentioned in studies. & 2010 & & \\
\hline
\end{tabular}


Table 3

The studies of the follow-up data in literatures

\begin{tabular}{|c|c|c|c|c|c|c|c|c|}
\hline \multirow[t]{2}{*}{ Study } & \multirow{2}{*}{$\begin{array}{l}\text { Case } \\
\text { numbers }\end{array}$} & \multirow{2}{*}{$\begin{array}{l}\text { Follow- } \\
\text { up } \\
\text { (months) }\end{array}$} & \multirow{2}{*}{$\begin{array}{l}\text { MSTS } \\
\text { score }\end{array}$} & \multicolumn{5}{|c|}{ Complications } \\
\hline & & & & Type 1 & Type 2 & ${ }_{3}^{\text {Type }}$ & Type 4 & Type 5 \\
\hline Current study & 6 & 19.6 & $62.3 \%$ & $0(0 \%)$ & $0(0 \%)$ & $\begin{array}{l}0 \\
(0 \%)\end{array}$ & $0(0 \%)$ & $1(16 \%)$ \\
\hline $\begin{array}{l}\text { Park et al [7] } \\
(2020)\end{array}$ & 12 & 17.8 & $87.2 \%$ & $1(8.3 \%)$ & $\begin{array}{l}1 \\
(8.3 \%)\end{array}$ & $\begin{array}{l}0 \\
(0 \%)\end{array}$ & $0(0 \%)$ & $0(0 \%)$ \\
\hline $\begin{array}{l}\text { Wang et al [21] } \\
\text { (2018) }\end{array}$ & 11 & 15.5 & $64 \%$ & $1(9.1 \%)$ & $\begin{array}{l}2 \\
(18.2 \%)\end{array}$ & $\begin{array}{l}0 \\
(0 \%)\end{array}$ & $0(0 \%)$ & $\begin{array}{l}1 \\
(9.1 \%)\end{array}$ \\
\hline $\begin{array}{l}\text { Liang et al [23] } \\
\text { (2017) }\end{array}$ & 35 & 20.5 & $63.7 \%$ & $9(25.7 \%)$ & $0(0 \%)$ & $\begin{array}{l}0 \\
(0 \%)\end{array}$ & $0(0 \%)$ & $0(0 \%)$ \\
\hline $\begin{array}{l}\text { Irene et al [19] } \\
(2017)\end{array}$ & 10 & 37 & $63.3 \%$ & $4(40 \%)$ & $0(0 \%)$ & $\begin{array}{l}0 \\
(0 \%)\end{array}$ & $4(40 \%)$ & $3(30 \%)$ \\
\hline $\begin{array}{l}\text { Guo et al [32] } \\
\text { (2010) }\end{array}$ & 18 & 41 & $71.7 \%$ & $\begin{array}{l}4 \\
(22.2 \%)\end{array}$ & $\begin{array}{l}1 \\
(5.6 \%)\end{array}$ & $\begin{array}{l}0 \\
(0 \%)\end{array}$ & $0(0 \%)$ & $\begin{array}{l}4 \\
(22.2 \%)\end{array}$ \\
\hline $\begin{array}{l}\text { Witte et al [24] } \\
\text { (2009) }\end{array}$ & 40 & 24 & $50 \%$ & $1(2.5 \%)$ & $\begin{array}{l}3 \\
(7.5 \%)\end{array}$ & $\begin{array}{l}0 \\
(0 \%)\end{array}$ & $18(45 \%)$ & $\begin{array}{l}7 \\
(17.5 \%)\end{array}$ \\
\hline $\begin{array}{l}\text { Dai et al [11] } \\
\text { (2007) }\end{array}$ & 10 & 34.3 & \# & $4(40 \%)$ & $1(10 \%)$ & $\begin{array}{l}0 \\
(0 \%)\end{array}$ & $0(0 \%)$ & $3(30 \%)$ \\
\hline $\begin{array}{l}\text { Hillmann et al } \\
\text { [38] (2003) }\end{array}$ & 16 & 45.5 & $37 \%$ & $1(6.3 \%)$ & $0(0 \%)$ & $\begin{array}{l}0 \\
(0 \%)\end{array}$ & $6(37.5 \%)$ & $3(18.8)$ \\
\hline
\end{tabular}

\section{Discussion}

Wide en bloc resection is critical for both primary malignant bone tumors and solitary bone metastases [30]. As the standard technique allows visualization of the osteotomy bone surface only through healthy and uncontaminated tissue, sometimes for large soft tissue masses, more soft tissue exposure is required [26]. In addition, the placement of osteotomy guide plates and prosthesis is often limited to the surgical window and surrounding soft tissue [31]. Therefore, we initially designed two combined approaches for tumor resection and pelvic reconstruction. Only one patient who underwent marginal excision developed local recurrence at 3 months after surgery. This complication did not occur in the other five patients, even including the patient who had died at the last follow-up. This is not surprising because previous studies have verified that there is a significant relationship between the incidence of local recurrence and the surgical margin [32], with 70\%-100\% of local recurrence cases resulting from marginal and intralesional resection [33]. In addition, there were no cases of nerve damage, skin necrosis or dislocation in the study. Some advantages of this combined approaches were observed. First, it could achieve the adequate exposure of soft tissue and facilitate the positioning of the guide plates and prostheses. Second, the contour of the tumor was visualized through different windows; as a result, the traction of the muscles and neurovascular bundles could be reduced. Third, 
this approach could reduce the risk of intraoperative tumor contamination, resulting in a lower rate of tumor recurrence. Last, it could efficiently preserve the blood supply by alleviating skin tension.

Rigorous preoperative planning is crucial in pelvic tumor surgery. Using a 3D-printed proportional pelvic model, surgeons can simulate hands-on surgical resection and reconstruction prior to the real operation [33]. Some cadaveric studies have already proven noninferior osteotomy accuracy using 3D-printed guide plates compared to navigation systems [31,34]. Nevertheless, because of the complicated preparation for the navigation procedure, the operative duration may increase and result in more bleeding [25]. In addition, the cost is another great disadvantage of surgical navigation system [35]. Gerant et al. [36] reported that major blood loss occurred during osteotomy. Osteotomy guide plates can help surgeons perform multiplanar osteotomy, achieve precise resection margins, shorten the operative duration and reduce intraoperative blood loss. In our series, pathological margins were negative after bone tumor resection. According to previous studies, the mean operative duration and intraoperative blood loss ranged from 258-445 min and 2206$6210 \mathrm{ml}$, respectively $[7,11,19,21,22,32,36]$. In the current study, the mean operative duration and intraoperative blood loss were reduced to $333 \mathrm{~min}$ and $1416 \mathrm{ml}$, respectively. Thus, the use of 3D-printed osteotomy guide plates was considered a key point to accelerate the osteotomy procedure.

Consideration should be taken by surgeons that many various complications may occur following pelvic reconstruction. In a systematic review [8], the overall complication rate after pelvic reconstruction was $50 \%$. As the most common, deep infection accounted for $14 \%$ of complications. Ji et al. [22] noted that neoadjuvant chemotherapy could have a negative influence on wound-related complications. In our series, no woundrelated complications, such as necrosis, seroma or dehiscence, were identified. Moreover, there were no cases of infection, even in the two patients who accepted preoperative neoadjuvant chemotherapy. We contributed these results to the use of intraoperative osteotomy guide plates and the design of the two combined approaches, which reduced the operative duration, blood loss and impact on soft tissue. Six patients all described significant alleviation of pain after surgery. The mean VAS score at 4 weeks and the mean MSTS score at 12 weeks postoperatively were 2 and 15.6, respectively, which are similar to those in the other studies $[7,11,19,21-24,32,38]$.

As another complication after pelvic reconstruction surgery, aseptic loosening occurs in up to $12 \%$ of patients due to the poor matching degree of conventional prostheses [36]. In our series, no cases of aseptic loosening, screw breakage, heterotopic ossification or periprosthetic fracture occurred. 3D-printed prostheses can precisely match any shape of residual pelvic and avoid repeated adjustments. The design of a porous metal surface permits osseointegration at the bone-implant interface, which is vital for implant longevity $[2,11,26$, 39]. In addition, poly-axial screws can also minimize shear stress to provide mechanical stability. Aside from these factors, the short follow-up period may be another reason for these results. Caution is advised if unexpected bone loss occurs during the operation, as it may be difficult to adapt the 3D-printed prostheses to the bone defect.

This study has some limitations. First, our 3D models were generated merely based on CT data, which may neglect the spread of the tumor within the bone. Second, the small sample size with a short follow-up limited this study. More cases should be included for further study, and we will continue to follow these patients. 


\section{Conclusion}

The 3D-printed prosthesis represents a potential alternative for reconstruction after malignant periacetabular tumor resection. The design of the two approaches and the use of osteotomy guide plates can yield good functional results, as well as a low rate of complication.

\section{List Of Abbreviations}

MSTS score, VAS score.

\section{Declarations}

Ethics approval and consent to participate:

This study has been performed in accordance with the Declaration of Helsinki.

\section{Consent for publication:}

Informed consent was obtained from all individual participants included in the study.

\section{Availability of data and materials:}

The datasets used during the current study are available from the corresponding author on reasonable request.

\section{Competing interests:}

The authors declare that they have no competing interests.

\section{Funding:}

Not applicable.

\section{Authors' contributions:}

Conceptualization, Methodology, Writing- Original draft preparation: [Yong-jie Zhao]; Investigation, Data curation: [Jing-yu Zhang]; Visualization, Investigation: [Xiao-qiang Deng, Xin-chong Du]; Software, Formal analysis: [Hao Zhang, Li Yang]; Investigation, Supervision, Validation: [Yong-cheng Hu]; Administration, Writing- Reviewing and Editing: [Xin-long Ma].

\section{Acknowledgements:}

Not applicable.

\section{References}


1. Bastian L, Hufner T, Mossinger E, Geerling J, Goesling T, Busche M, Kendoff D, Bading S, Rosenthal H, Krettek C (2003) [Integration of modern technologies in therapy of sarcomas of the pelvis. Computerassisted hemipelvectomy and implantation of a "custom-made" Bonit gentamycin coated partial pelvic prosthesis]. Unfallchirurg 106 (11):956-962. doi:10.1007/s00113-003-0680-z

2. Guo W, Li D, Tang X, Yang Y, Ji T (2007) Reconstruction with modular hemipelvic prostheses for periacetabular tumor. Clin Orthop Relat Res 461:180-188. doi:10.1097/BLO.0b013e31806165d5

3. Jansen JA, van de Sande MA, Dijkstra PD (2013) Poor long-term clinical results of saddle prosthesis after resection of periacetabular tumors. Clin Orthop Relat Res 471 (1):324-331. doi:10.1007/s11999-0122631-x

4. Parry MC, Laitinen M, Albergo J, Jeys L, Carter S, Gaston CL, Sumathi V, Grimer RJ (2016) Osteosarcoma of the pelvis. Bone Joint J 98-B (4):555-563. doi:10.1302/0301-620X.98B4.36583

5. Iqbal T, Wang L, Li D, Dong E, Fan H, Fu J, Hu C (2019) A general multi-objective topology optimization methodology developed for customized design of pelvic prostheses. Med Eng Phys 69:8-16. doi:10.1016/j.medengphy.2019.06.008

6. Kontovounisios C, Tekkis P, Bello F (2019) 3D imaging and printing in pelvic colorectal cancer: 'The New Kid on the Block'. Tech Coloproctol 23 (2):171-173. doi:10.1007/s10151-018-1922-y

7. Park JW, Kang HG, Kim JH, Kim HS (2020) The application of 3D-printing technology in pelvic bone tumor surgery. J Orthop Sci. doi:10.1016/j.jos.2020.03.004

8. Brown TS, Salib CG, Rose PS, Sim FH, Lewallen DG, Abdel MP (2018) Reconstruction of the hip after resection of periacetabular oncological lesions: a systematic review. Bone Joint J 100-B (1 Supple A):2230. doi:10.1302/0301-620X.100B1.BJJ-2017-0548.R1

9. Li X, Ji T, Huang S, Wang C, Zheng Y, Guo W (2020) Biomechanics study of a 3D printed sacroiliac joint fixed modular hemipelvic endoprosthesis. Clin Biomech (Bristol, Avon) 74:87-95.

doi:10.1016/j.clinbiomech.2020.02.014

10. Carter SR, Eastwood DM, Grimer RJ, Sneath RS (1990) Hindquarter amputation for tumours of the musculoskeletal system. J Bone Joint Surg Br 72 (3):490-493. doi:10.1302/0301-620X.72B3.2341454

11. Dai KR, Yan MN, Zhu ZA, Sun YH (2007) Computer-aided custom-made hemipelvic prosthesis used in extensive pelvic lesions. J Arthroplasty 22 (7):981-986. doi:10.1016/j.arth.2007.05.002

12. Ham SJ, Schraffordt Koops H, Veth RP, van Horn JR, Eisma WH, Hoekstra HJ (1997) External and internal hemipelvectomy for sarcomas of the pelvic girdle: consequences of limb-salvage treatment. Eur J Surg Oncol 23 (6):540-546. doi:10.1016/s0748-7983(97)93173-5

13. Ji T, Guo W, Yang RL, Tang XD, Wang YF (2013) Modular hemipelvic endoprosthesis reconstruction-experience in 100 patients with mid-term follow-up results. Eur J Surg Oncol 39 (1):53-60. doi:10.1016/j.ejso.2012.10.002

14. Puri A, Gulia A, Pruthi M (2014) Outcome of surgical resection of pelvic osteosarcoma. Indian J Orthop 48 (3):273-278. doi:10.4103/0019-5413.132515

15. Aydinli U, Akesen B, Yalcinkaya U, Hakyemez B, Serifoglu R (2012) Iliosacral fixation after type-1 hemipelvectomy: a novel technique. Acta Orthop Belg 78 (3):393-397 
16. Delloye C, Banse X, Brichard B, Docquier PL, Cornu O (2007) Pelvic reconstruction with a structural pelvic allograft after resection of a malignant bone tumor. J Bone Joint Surg Am 89 (3):579-587. doi:10.2106/JBJS.E.00943

17. Ogura K, Sakuraba M, Miyamoto S, Fujiwara T, Chuman H, Kawai A (2015) Pelvic ring reconstruction with a double-barreled free vascularized fibula graft after resection of malignant pelvic bone tumor. Arch Orthop Trauma Surg 135 (5):619-625. doi:10.1007/s00402-015-2197-7

18. Traub F, Andreou D, Niethard M, Tiedke C, Werner M, Tunn PU (2013) Biological reconstruction following the resection of malignant bone tumors of the pelvis. Sarcoma 2013:745360. doi:10.1155/2013/745360

19. Barrientos-Ruiz I, Ortiz-Cruz EJ, Peleteiro-Pensado M (2017) Reconstruction After Hemipelvectomy With the Ice-Cream Cone Prosthesis: What Are the Short-term Clinical Results? Clin Orthop Relat Res 475 (3):735-741. doi:10.1007/s11999-016-4747-x

20. Zhang Y, Tang X, Ji T, Yan T, Yang R, Yang Y, Wei R, Liang H, Guo W (2018) Is a Modular Pediclehemipelvic Endoprosthesis Durable at Short Term in Patients Undergoing Enneking Type I + II Tumor Resections With or Without Sacroiliac Involvement? Clin Orthop Relat Res 476 (9):1751-1761. doi:10.1007/s11999.0000000000000121

21. Wang B, Hao Y, Pu F, Jiang W, Shao Z (2018) Computer-aided designed, three dimensional-printed hemipelvic prosthesis for peri-acetabular malignant bone tumour. Int Orthop 42 (3):687-694. doi:10.1007/s00264-017-3645-5

22. Ji T, Yang Y, Tang X, Liang H, Yan T, Yang R, Guo W (2020) 3D-Printed Modular Hemipelvic Endoprosthetic Reconstruction Following Periacetabular Tumor Resection: Early Results of 80 Consecutive Cases. J Bone Joint Surg Am 102 (17):1530-1541. doi:10.2106/JBJS.19.01437

23. Liang H, Ji T, Zhang Y, Wang Y, Guo W (2017) Reconstruction with 3D-printed pelvic endoprostheses after resection of a pelvic tumour. Bone Joint J 99-B (2):267-275. doi:10.1302/0301-620X.99B2.BJJ-20160654.R1

24. Witte D, Bernd L, Bruns J, Gosheger G, Hardes J, Hartwig E, Lehner B, Melcher I, Mutschler W, Schulte M, Tunn PU, Wozniak W, Zahlten-Hinguranage A, Zeifang F (2009) Limb-salvage reconstruction with MUTARS hemipelvic endoprosthesis: a prospective multicenter study. Eur J Surg Oncol 35 (12):13181325. doi:10.1016/j.ejso.2009.04.011

25. Chen X, Xu L, Wang Y, Hao Y, Wang L (2016) Image-guided installation of 3D-printed patient-specific implant and its application in pelvic tumor resection and reconstruction surgery. Comput Methods Programs Biomed 125:66-78. doi:10.1016/j.cmpb.2015.10.020

26. Wong KC, Kumta SM, Geel NV, Demol J (2015) One-step reconstruction with a 3D-printed, biomechanically evaluated custom implant after complex pelvic tumor resection. Comput Aided Surg 20 (1):14-23. doi:10.3109/10929088.2015.1076039

27. Enneking WF, Dunham WK (1978) Resection and reconstruction for primary neoplasms involving the innominate bone. J Bone Joint Surg Am 60 (6):731-746

28. Uehara K, Ogura K, Akiyama T, Shinoda Y, Iwata S, Kobayashi E, Tanzawa Y, Yonemoto T, Kawano H, Kawai A (2017) Reliability and Validity of the Musculoskeletal Tumor Society Scoring System for the Upper Extremity in Japanese Patients. Clin Orthop Relat Res 475 (9):2253-2259. doi:10.1007/s11999017-5390-x. 
29. Henderson ER, Groundland JS, Pala E, et al (2011) Failure mode classification for tumor endoprostheses: retrospective review of five institutions and a literature review. J Bone Joint Surg Am 93 (5):418-429. Doi:10.2106/JBJS.J.00834.

30. Ruggieri $P$, Mavrogenis AF, Angelini A, Mercuri M (2011) Metastases of the pelvis: does resection improve survival? Orthopedics 34 (7):236-244. doi:10.3928/01477447-20110526-07.

31. Sallent A, Vicente M, Reverte MM, Lopez A, Rodriguez-Baeza A, Perez-Dominguez M, Velez R (2017) How 3D patient-specific instruments improve accuracy of pelvic bone tumour resection in a cadaveric study. Bone Joint Res 6 (10):577-583. doi:10.1302/2046-3758.610.BJR-2017-0094.R1.

32. Guo Z, Li J, Pei GX, Li XD, Wang Z (2010) Pelvic reconstruction with a combined hemipelvic prostheses after resection of primary malignant tumor. Surg Oncol 19 (2):95-105. doi:10.1016/j.suronc.2009.04.003.

33. Fang X, Yu Z, Xiong Y, Yuan F, Liu H, Wu F, Zhang W, Luo Y, Song L, Tu C, Duan H (2018) Improved virtual surgical planning with 3D- multimodality image for malignant giant pelvic tumors. Cancer Manag Res 10:6769-6777. doi:10.2147/CMAR.S185737.

34. Wong KC, Sze KY, Wong IO, Wong CM, Kumta SM (2016) Patient-specific instrument can achieve same accuracy with less resection time than navigation assistance in periacetabular pelvic tumor surgery: a cadaveric study. Int J Comput Assist Radiol Surg 11 (2):307-316. doi:10.1007/s11548-015-1250-x.

35. Ould-Slimane M, Thong P, Perez A, Roussignol X, Dujardin FH (2016) The role of Intraoperative 3D navigation for pelvic bone tumor resection. Orthop Traumatol Surg Res 102 (6):807-811. doi:10.1016/j.otsr.2016.03.019.

36. Cernat E, Docquier PL, Paul L, Banse X, Codorean IB (2016) Patient Specific Instruments for Complex Tumor Resection-Reconstruction Surgery within the Pelvis: A Series of 4 Cases. Chirurgia (Bucur) 111 (5):439-444. doi:10.21614/chirurgia.111.5.439.

37. Handels H, Ehrhardt J, Plotz W, Poppl SJ (1999) Computer-assisted planning and simulation of hip operations using virtual three-dimensional models. Stud Health Technol Inform 68:686-689.

38. Hillmann A, Hoffmann C, Gosheger G, Rodl R, Winkelmann W, Ozaki T (2003) Tumors of the pelvis: complications after reconstruction. Arch Orthop Trauma Surg 123 (7):340-344. doi:10.1007/s00402-0030543-7.

39. Fan H, Fu J, Li X, Pei Y, Li X, Pei G, Guo Z (2015) Implantation of customized 3-D printed titanium prosthesis in limb salvage surgery: a case series and review of the literature. World J Surg Oncol 13:308. doi:10.1186/s12957-015-0723-2.

\section{Figures}




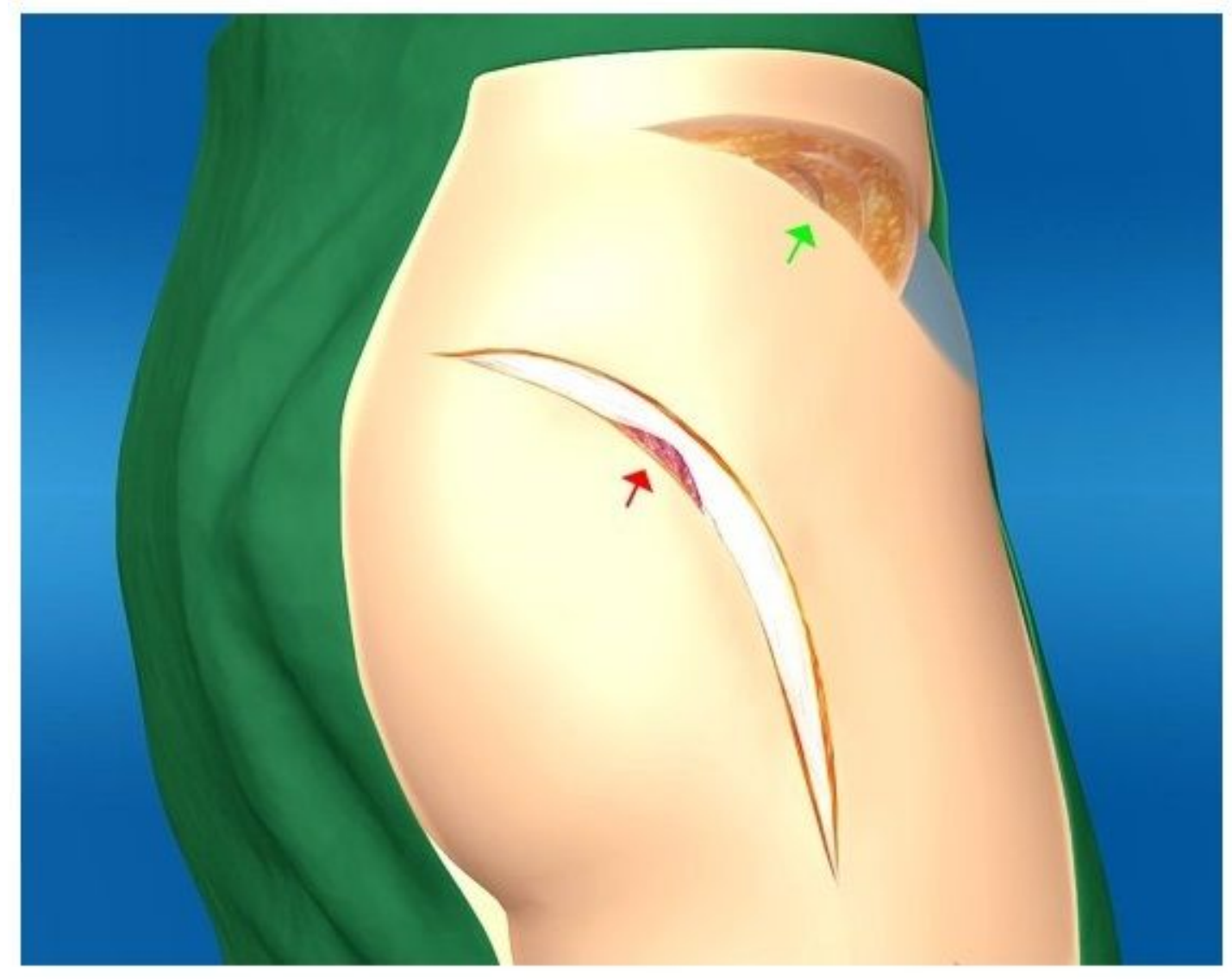

Figure 1

The design of two approaches: ilioinguinal approach (green arrow) and Kocher-Langenbeck approach (red arrow).
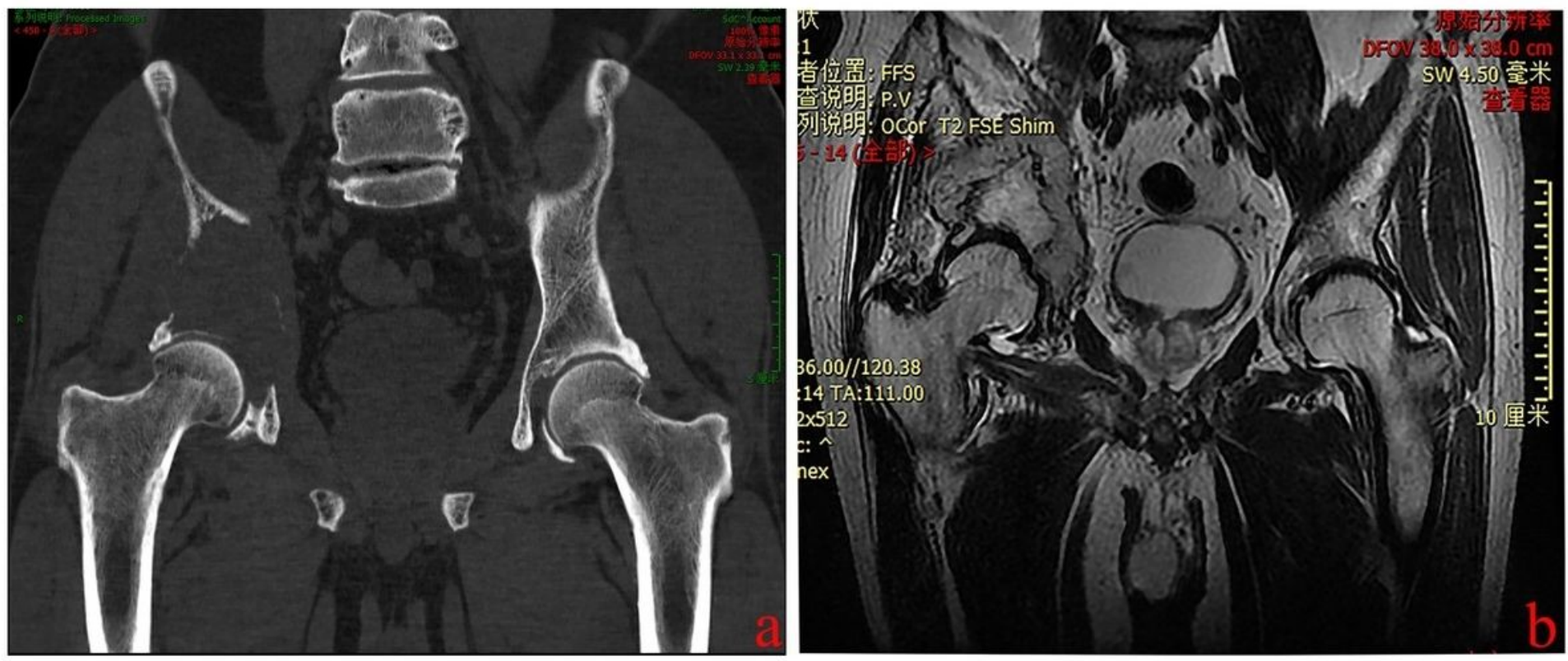

Figure 2 
A man aged 69 years with a metastatic renal cancer involved the acetabulum. (a) Preoperative CT scan shows the malignant tumor has invaded the peri-acetabular region. (b) MRI shows tumor involvement of the acetabulum with an extensive soft-tissue mass.
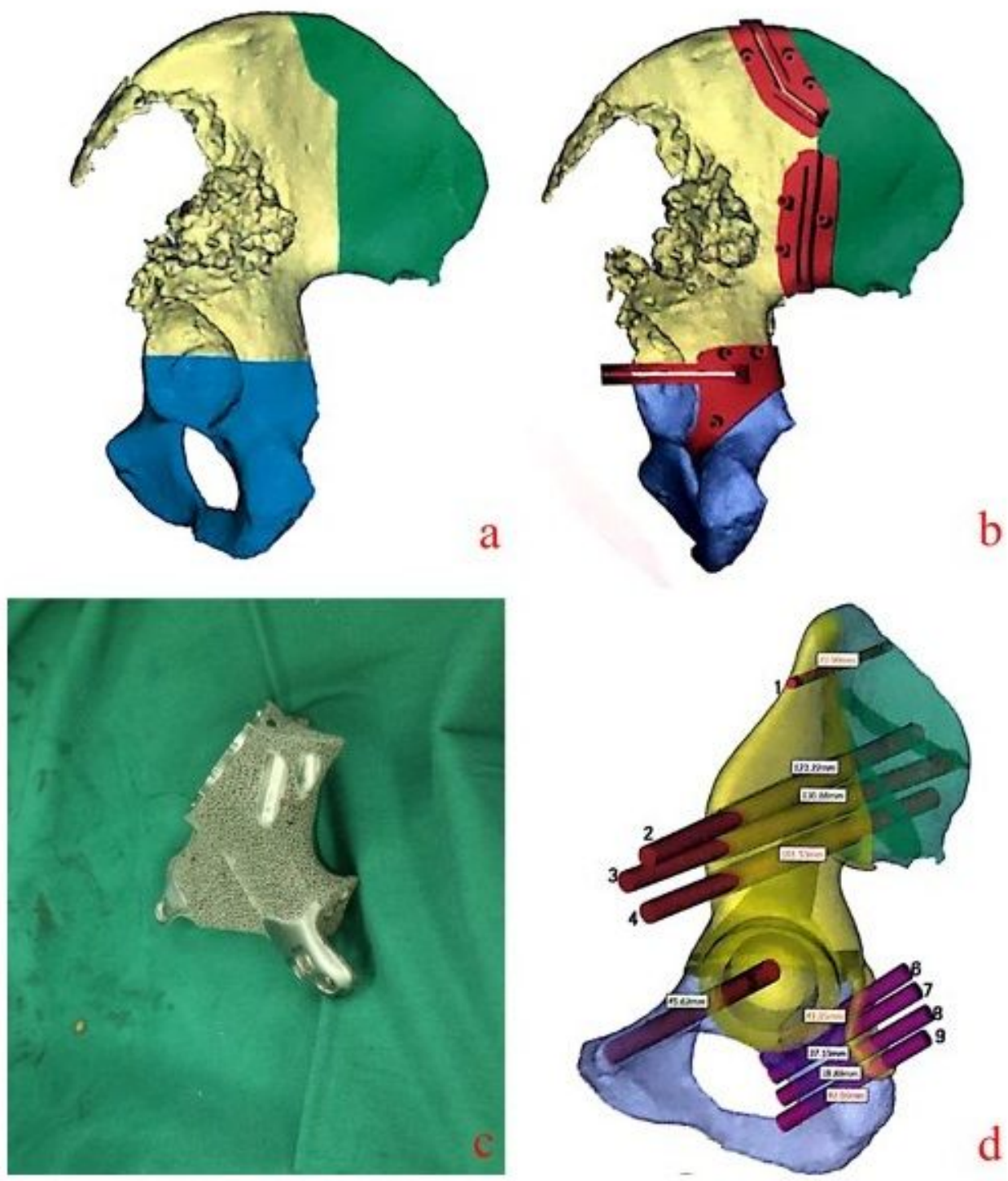

\section{Figure 3}

Preoperative planning. (a) The contour of the tumor is visualized in 3D models. (b) The osteotomy guide plates are designed based on the CT data. (c) An individualized prosthesis with a porous structure is manufactured. (d) The position and length were planned based on the bone thickness, residual bone mass and loading orientation to minimize shear stress. 

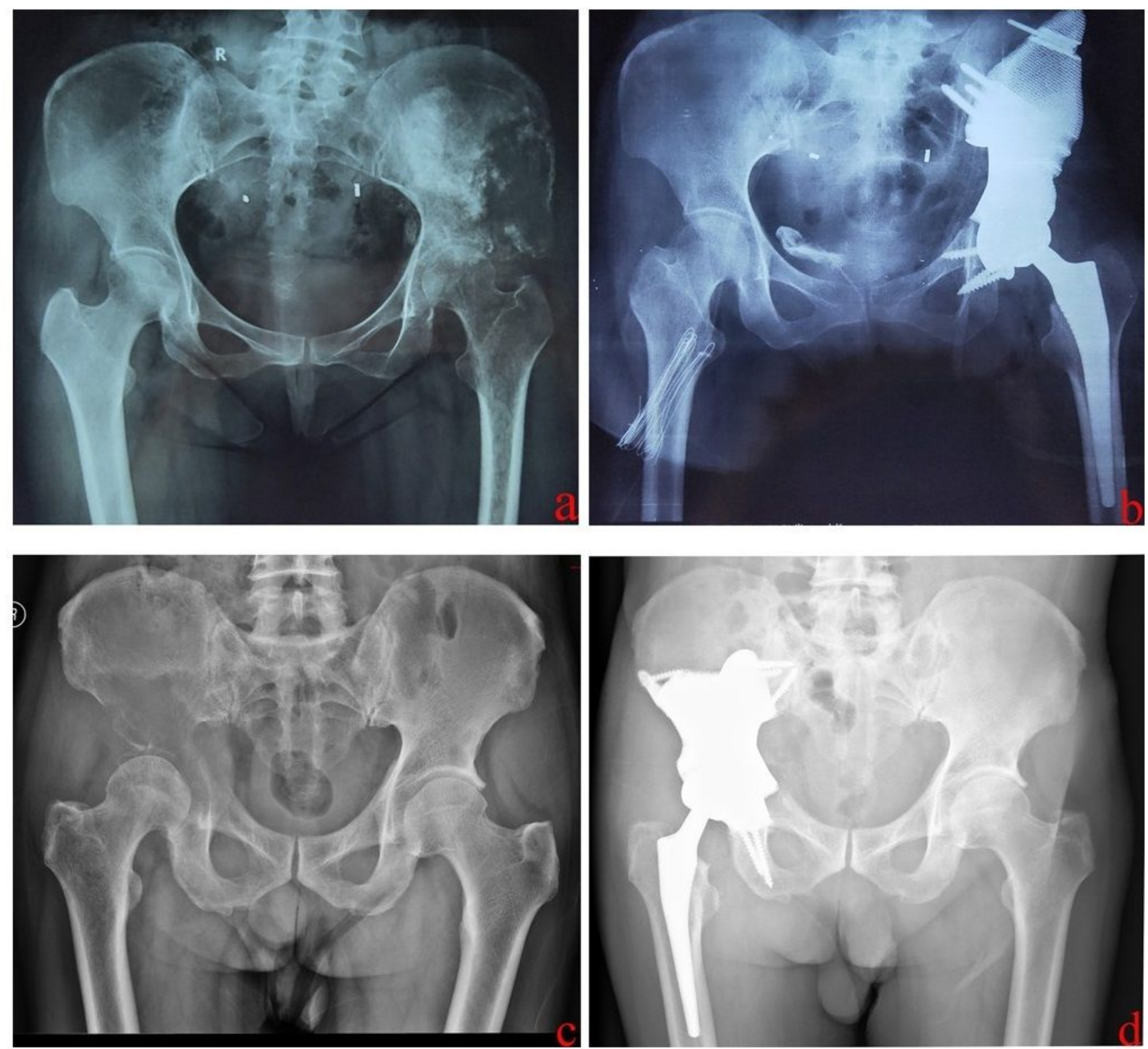

\section{Figure 4}

Preoperative and postoperative radiography. ( $\mathrm{a} \square \mathrm{c})$ The tumors involved the left and right acetabulum, respectively. (b\d) After surgery, the pelvic ring was obtained anatomic reconstruction and the inclination and anteversion of acetabular cup was identical with the contralateral side.

\section{Supplementary Files}

This is a list of supplementary files associated with this preprint. Click to download.

- Additionalfile1.mp4 